\title{
Gene Mutations as Emerging Biomarkers and Therapeutic Targets for Relapsed Acute Myeloid Leukemia
}

\author{
Habsah Aziz ${ }^{1}$, Chow Y. Ping ${ }^{1}$, Hamidah Alias ${ }^{2}$, Nurul-Syakima Ab Mutalib ${ }^{1}$ and \\ Rahman Jamal ${ }^{1 *}$ \\ ' UKM Medical Molecular Biology Institute, Universiti Kebangsaan Malaysia, Kuala Lumpur, Malaysia, ${ }^{2}$ Department of \\ Paediatrics, Faculty of Medicine, Universiti Kebangsaan Malaysia, Kuala Lumpur, Malaysia
}

OPEN ACCESS

Edited by:

Moyra Smith,

University of California, Irvine,

United States

Reviewed by:

Naval Daver,

University of Texas MD Anderson

Cancer Center, United States

Yunbao Pan

Wuhan University, China

*Correspondence:

Rahman Jamal

rahmanj@ppukm.ukm.edu.my

Specialty section:

This article was submitted to Cancer Molecular Targets and

Therapeutics,

a section of the journal

Frontiers in Pharmacology

Received: 21 July 2017 Accepted: 24 November 2017 Published: 07 December 2017

Citation:

Aziz $\mathrm{H}$, Ping $\mathrm{CY}$, Alias $\mathrm{H}$,

Ab Mutalib N-S and Jamal $R$ (2017)

Gene Mutations as Emerging

Biomarkers and Therapeutic Targets for Relapsed Acute Myeloid Leukemia.

Front. Pharmacol. 8:897.

doi: 10.3389/fphar.2017.00897
It is believed that there are key differences in the genomic profile between adult and childhood acute myeloid leukemia (AML). Relapse is the significant contributor of mortality in patients with $A M L$ and remains as the leading cause of cancer death among children, posing great challenges in the treatment of AML. The knowledge about the genomic lesions in childhood AML is still premature as most genomic events defined in children were derived from adult cohorts. However, the emerging technologies of next generation sequencing have narrowed the gap of knowledge in the biology of AML by the detection of gene mutations for each sub-type which have led to the improvement in terms of prognostication as well as the use of targeted therapies. In this review, we describe the recent understanding of the genomic landscape including the prevalence of mutation, prognostic impact, and targeted therapies that will provide an insight into the pathogenesis of AML relapse in both adult and childhood cases.

Keywords: acute myeloid leukemia, mutation, adult, childhood, relapse, biomarker

\section{INTRODUCTION}

Acute myeloid leukemia (AML) is a blood cancer which characterized by the infiltration of proliferative, clonal, abnormally differentiated, and occasionally poorly differentiated cells of the hematopoietic system (Döhner et al., 2015), as a consequence of arrested myeloid differentiation. The biology of AML is associated with its age variation, as evidenced by the significant variability of genomic alterations in AML from infancy to adulthood. There is also a significant age-based incidence, with elevated incidence reported in both infants and older adults (Meshinchi and Arceci, 2007; Pui et al., 2011; Jay and Schiffer, 2012; Tasian et al., 2014; Tarlock and Meshinchi, 2015).

AML is frequently diagnosed in very young children and comprises of nearly $25 \%$ of childhood leukemias. Nearly 800 cases of children and adolescents are diagnosed with AML in the United States annually (Meshinchi and Arceci, 2007; Pui et al., 2011; Tasian et al., 2014). Adults have a higher incidence and AML is generally considered as a disease of the elderly with a median age at diagnosis of around 70 years (Jay and Schiffer, 2012; Tarlock and Meshinchi, 2015). The incidence increases with age, evidenced by 1.3 per 100000 population in patients aged less than 65 years old as compared to 12.2 per 100000 population in patients aged over 65 years old (De Kouchkovsky and Abdul-Hay, 2016). Approximately 19,950 new AML cases were diagnosed and 10,430 patients succumbed to the disease in the USA in 2016 (Howlader et al., 2017). In Malaysia, 2,477 cases with 1,330 new cases of AML were reported for a period of 5 years beginning 2007 until 
2011 (Ab Manan et al., 2016). As such, new treatment strategies are urgently needed to improve the patients' survival outcome.

The treatment of AML has not changed drastically since 30 years ago (Döhner et al., 2010), and only $60-70 \%$ of childhood AML patients achieved long-term cure with the current intensive cytotoxic chemotherapy regimens (Pui et al., 2011; Moore et al., 2013). The percentage of survival is even lower in adult patients aged 60 years or younger, ranging from 35 to $40 \%$. The cure rate is only 5 to $15 \%$ for patients aged above 60 years (Döhner et al., 2010, 2015). Morbidity and mortality in patients with AML is significantly contributed by the primary chemo-refractory disease and relapses. Hence better understanding of the genetic lesions underpinning refractory and relapsed AML is pivotal for developing new therapeutic strategies.

\section{RELAPSED ACUTE MYELOID LEUKEMIA}

Relapse after achieving remission remains as one of the major obstacles in improving the patients' overall survival rate and to achieve long term survival for patients with AML. In adult AML, recurrence usually occurs within 3 years post-treatment in most patients (Döhner et al., 2015). Based on the study carried out by the Eastern Cooperative Oncology Group (ECOG) between 1983 and 1997 on newly diagnosed adult AML patients aged $>55$ years, $65 \%$ of them relapsed and had a median survival of 4.7 months, with only $6 \%$ who survived more than 5 years. In contrast, better outcome was reported in younger adult patients (aged $<55$ years) in which only 35\% of them relapsed (Rowe et al., 2005). The poorer outcome in older patients may be partly attributed to their lower tolerance to side effects induced by intensive chemotherapies (Döhner et al., 2015).

Meanwhile, the median time to relapse in childhood AML has been rather stable for consecutive decades (1976-1991:0.93 years, 1991-1997:0.76 years, 2002-2008:0.8 years), (Rubnitz et al., 2014) and relapsed AML remains as the leading cause of cancer deaths among children accounting for more than 50\% of childhood leukemia-related deaths (Moore et al., 2013). The response rate to induction chemotherapy in children with AML is relatively higher than adults. This may be due to the children having a higher tolerance level against intensive chemotherapy, lower prevalence of co-morbidities and more intensive supportive care measures (Tasian et al., 2014).

The differences between childhood and adult AML can be explained by the distinct inherent biology of the disease which is inclusive of the discordant incidences of leukemia-associated genetic alterations, pattern of epigenetic changes, and rates of remission induction (Radhi et al., 2010; Creutzig et al., 2012; Puumala et al., 2013; Schuback et al., 2013). The data derived from studies involving both groups of AML patients suggested that there is a pressing need to decrease the number of cases who will relapse and to improve cure rates.

Certainly, major improvement in the treatment strategies is required to improve the success rate for relapsed AML. There is no specific tailored therapy that suitable for every patient. The treatment of relapsed AML is rather varied and dependent on several factors such as age, general health status, remission duration, and genetic aberrations. In the adult setting, most of the relapsed AML patients will be administered with intensified salvage regimens such as MEC (mitoxantrone, etoposide, cytarabine), or FLAG-IDA (fludarabine, granulocyte colony-stimulating factor, idarubicin) followed by allogeneic hematopoietic stem cell transplant (HSCT) whereas low intensity therapy or best supportive care will be offered to adult patients who are physically weak and could not tolerate high dose therapies (Döhner et al., 2015). For children with relapsed AML, reinduction with chemotherapy using FLAG is commonly practiced with good early response by adding the liposomal daunorubicin to FLAG (Kaspers et al., 2013; Creutzig et al., 2014). Remarkably, CBF-AML relapsed patients who received FLAG plus liposomal daunorubicin had a significantly better 4year overall survival ( 82 vs. $58 \%$ ) as compared to those who received FLAG alone (Kaspers et al., 2013). Similar to adult AML, allogeneic HSCT is offered when suitable matched donor is available and the patient is in remission.

Thus far, the prognosis of relapsed AML remains dismal even with allogeneic HSCT (Thol et al., 2015). It is believed that the leukemia stem cells (LSCs) are the source of chemotherapy resistance and likely responsible for the relapse. The LSCs are similar in characteristics to hematopoietic stem cells (HSCs) but they give rise to undifferentiated leukemic blasts (Guzman et al., 2007a). Liran et al. identified pre-leukemic HSCs in the remission sample of an AML patient that harbored DNMT3A mutation. Unlike the AML blasts, these pre-leukemic HSCs survived the induction chemotherapy (Shlush et al., 2014). Few agents, including parthenolide (PTL) (Guzman et al., 2005, 2007b), 4-benzyl-2-methyl-1,2,4-thiadiazolidine-3,5-dione (TDZD-8) (Guzman et al., 2007a), and Fenretinide (Zhang et al., 2013) have been shown to be effective in eradicating LSCs by targeting the LSCs enriched $\mathrm{CD} 34^{+} \mathrm{CD} 38^{-}$population. Further studies are warranted to evaluate the effectiveness of these agents as the treatment regimens for relapsed AML.

The genome profiling of matched de novo and relapsed AML by whole genome sequencing (WGS) has revealed the existence of two major patterns of clonal evolution underlying AML progression. The first pattern suggested that the founding clone gained additional mutations and evolved into the relapse clone, whereas the second pattern suggested that the subclone of the founding clone which survived initial therapy gained additional mutations and expanded at relapse (Ding et al., 2012). Therefore, understanding of the AML genome and development of targeted therapies which capable to eliminate both founding clones and subclones is key to improving the survival of relapsed AML.

\section{COMMONLY MUTATED GENES IN AML AND RELAPSE PROGNOSIS}

Cytogenetic profiling remains as the gold standard for guiding risk-adapted treatment plan in AML patients. However, the high relapse risk among AML patients suggested that a more defined risk stratification strategy and better treatment regimens are needed. In recent years, a long list of mutated genes was identified through various sequencing and genotyping approaches. In this 
review, we describe the prevalence and prognostic impact of genes which are frequently mutated in both childhood and adult AML according to the gene function categories. The prevalence and prognostic impact from various studies are illustrated in Tables 1, 2.

\section{Nucleophosmin}

The nucleophosmin (NPM1) gene encodes for a phosphoprotein (Döhner et al., 2015; Tarlock and Meshinchi, 2015) which is involved in the biogenesis of ribosome, duplication of centrosome during mitosis, cell proliferation, and apoptosis induction through p53 and p19Arf (Falini et al., 2007). NPM1 mutants have been shown to cause aberrant cytoplasmic localization of NPM1 and NPM1-interacting proteins, as well as impaired function of the nucleolar wild-type NPM1 protein (Döhner et al., 2015; Tarlock and Meshinchi, 2015). NPM1 was found commonly mutated in both adult and childhood AML patients, with a higher incidence reported in adults (24-29\%) (Mardis et al., 2009; Grossmann et al., 2012; Cancer Genome Atlas Research, 2013) than in children (3-11\%) (Brown et al., 2007; Thol et al., 2011; Liang et al., 2013; Rubio et al., 2016; Shiba et al., 2016). The incidence appeared to be higher in cytogenetically normal AML (CN-AML), with $48 \%$ in adults (Döhner et al., 2005) and 15\% in childhood AML (Rubio et al., 2016). NPM1 mutations have also been shown to be predictive of a favorable prognosis with a reduced risk of relapse in AML patients (Döhner et al., 2005; Papaemmanuil et al., 2016).

\section{DNA Methylation}

DNA methyltransferase 3 alpha (DNMT3A), isocitrate dehydrogenase 1 and 2 (IDH1 and IDH2) and tet methylcytosine dioxygenase 2 (TET2) are involved in regulating the methylation of the genome (Langemeijer et al., 2011; Shah and Licht, 2011; Lu et al., 2012; Liang et al., 2013; Aslanyan et al., 2014; Ibrahem et al., 2014). DNA methyltransferases (DNMTs) act as a catalyst to convert cytosine to 5-methylcytosine (Shah and Licht, 2011). DNMT3A mutation was first identified in an AML patient by WGS (Ley et al., 2010). This mutation is rare in childhood AML, ranging from 0 to 2\% (Ho et al., 2011; Thol et al., 2011; Liang et al., 2013) but the occurrence rate has been reported in 22-26\% of adult cases (Ley et al., 2010; Cancer Genome Atlas Research, 2013; Shlush et al., 2014). Patients who harbored DNMT3A mutations showed unfavorable outcomes and higher relapse rates (Marková et al., 2012). An even worse prognosis was observed in $\mathrm{CN}-\mathrm{AML}$ patients with this mutation and high dose of anthracycline chemotherapy has been recommended for this subgroup of patients (Marková et al., 2012; Patel et al., 2012; Shivarov et al., 2013). A meta-analysis involving 12 studies with a total of 6,377 patients with DNMT3A mutations showed poor prognostic impact on the overall survival, relapse free survival, and event free survival (Tie et al., 2014).

IDH1 mutations that affect the arginine residue at position R132 or R170, and IDH2 at R140 or R172 (Abbas et al., 2010; Radhi et al., 2010; Green et al., 2011; Rakheja et al., 2012; Shih et al., 2012) will impair histone demethylation (Lu et al., 2012). IDH1 mutation was first discovered in 2009 by the WGS in an adult AML genome (Mardis et al., 2009). IDH1 and
IDH2 mutations were rarely detected in childhood AML, with a frequency of $0-1$ and $1-2 \%$ respectively, but a higher incidence was seen in children with CN-AML (Ho et al., 2010, 2011; Andersson et al., 2011; Damm et al., 2011; Liang et al., 2013). In contrast, $I D H 1$ and $I D H 2$ were detected more commonly in adult AML, with a prevalence of 4-9 and 8-19\% respectively (Mardis et al., 2009; Ho et al., 2010; Döhner et al., 2015). Remarkably, a higher frequency of IDH1/IDH2 (20\%) was detected in adult AML via the WGS and WES approach (Cancer Genome Atlas Research, 2013), suggesting NGS could be a more sensitive approach in detecting subclonal mutations in heterogenous AML blast cells. Notably, patients with IDH1 mutations appeared to have more unfavorable outcomes compared to those with $\mathrm{IDH} 2$ mutations (Abbas et al., 2010; Patel et al., 2012) and shorter overall survival compared to patients without IDH mutation (Aref et al., 2015). Moreover, patients with double positive IDH and NPM1 mutations, but FLT3-ITD-negative, showed a shorter relapse free survival (Paschka et al., 2010).

TET2 converts methylcytosine to 5-hydroxymethylcytosine and has a role in regulating myelopoiesis (Shih et al., 2012). Loss of function mutation in TET2 decreased DNA hydroxymethylation (Aslanyan et al., 2014). TET2 was shown to be frequently mutated in adult AML (8-28\%) as compared to childhood AML (1-7\%) (Langemeijer et al., 2011; Weissmann et al., 2012; Cancer Genome Atlas Research, 2013; Liang et al., 2013; Kao et al., 2014; Kutny et al., 2015). The prognostic effect of TET2 mutation remains controversial. No significant impact on relapse free survival was observed in a large cohort of younger adult AML patients (Gaidzik et al., 2012) and no difference in relapse incidence at 5 years in CN-AML patients with or without TET2 mutations (Ahn et al., 2015), whilst other studies demonstrated that TET2 mutations were correlated with inferior outcomes in favorable-risk CN-AML (Patel et al., 2012) and failure to achieve complete remission in childhood AML (Kutny et al., 2015).

\section{Activated Signaling Pathway}

Fms-like Tyrosine Kinase 3 (FLT3) encodes for a receptor tyrosine kinase which is a membrane-bound receptor with an intrinsic tyrosine kinase domain. Internal tandem duplication (ITD) of the juxtamembrane domain and point mutations of the tyrosine kinase domain (TKD) in FLT3 have been shown to result in the constitutive activation of the receptor kinase activity (Nakao et al., 1996; Tarlock and Meshinchi, 2015). In both adult and childhood AML, the incidence of FLT3 ITD (1537 and $10-21 \%$ respectively) was higher compared to FLT3 TKD (10 and 7\%) (Cloos et al., 2006; Thol et al., 2011; Damm et al., 2012; Grossmann et al., 2012; Cancer Genome Atlas Research, 2013; Liang et al., 2013; Kao et al., 2014; Rubio et al., 2016; Shiba et al., 2016). FLT3-ITD was associated with poor outcomes and high relapse rate, and the duplication has been shown to persist in both diagnosis and relapse samples with no significant changes in frequency (Kottaridis et al., 2002; Shih et al., 2002; Cloos et al., 2006). Even though allogeneic stem cell transplant or the use of FLT3 inhibitors has been proposed as promising treatment approaches for patients harboring FLT3 mutations, the results have been disappointing due to the high relapse 
TABLE 1 | The Prevalence of gene mutation in AML according to functional categories.

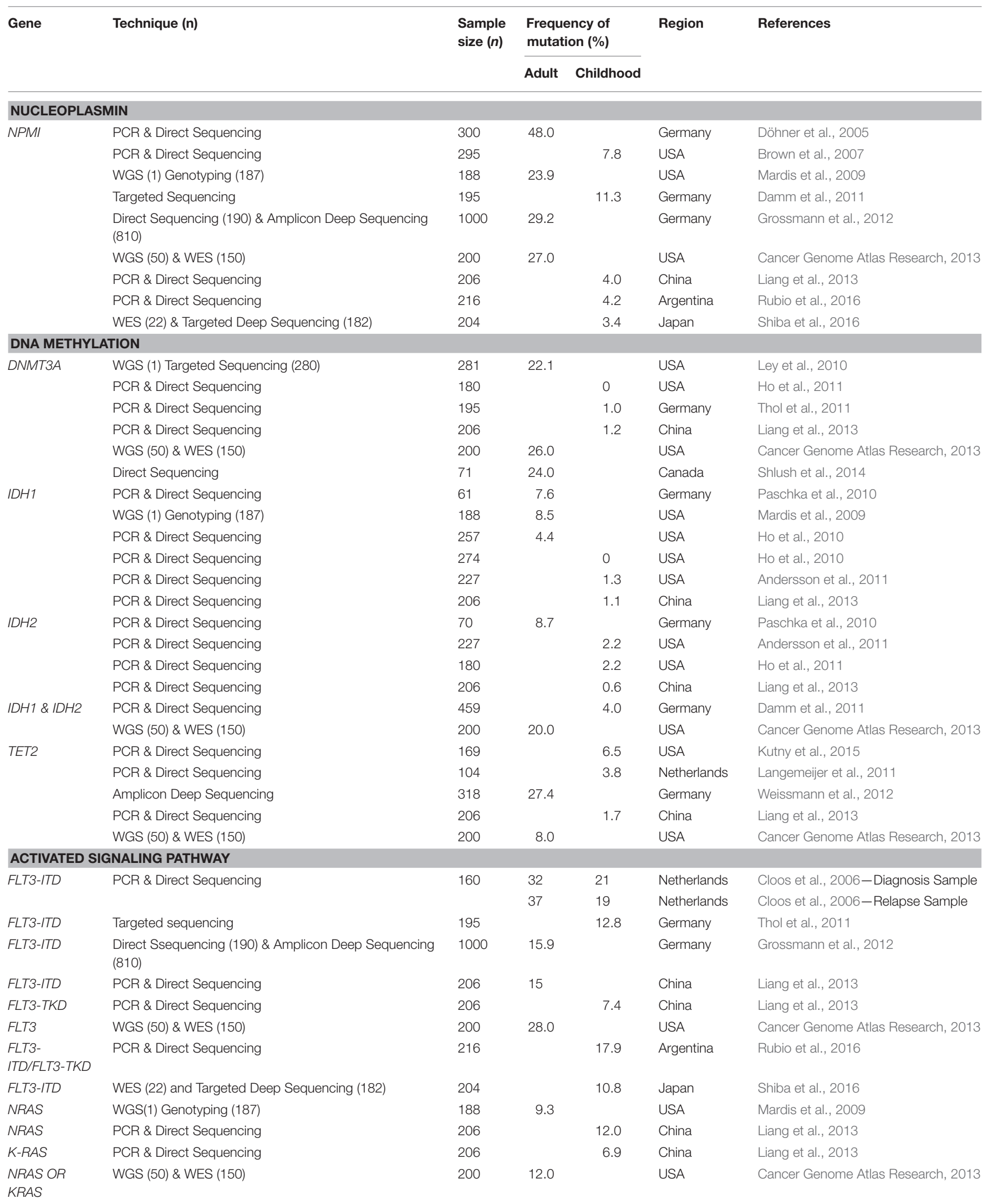


TABLE 1 | Continued

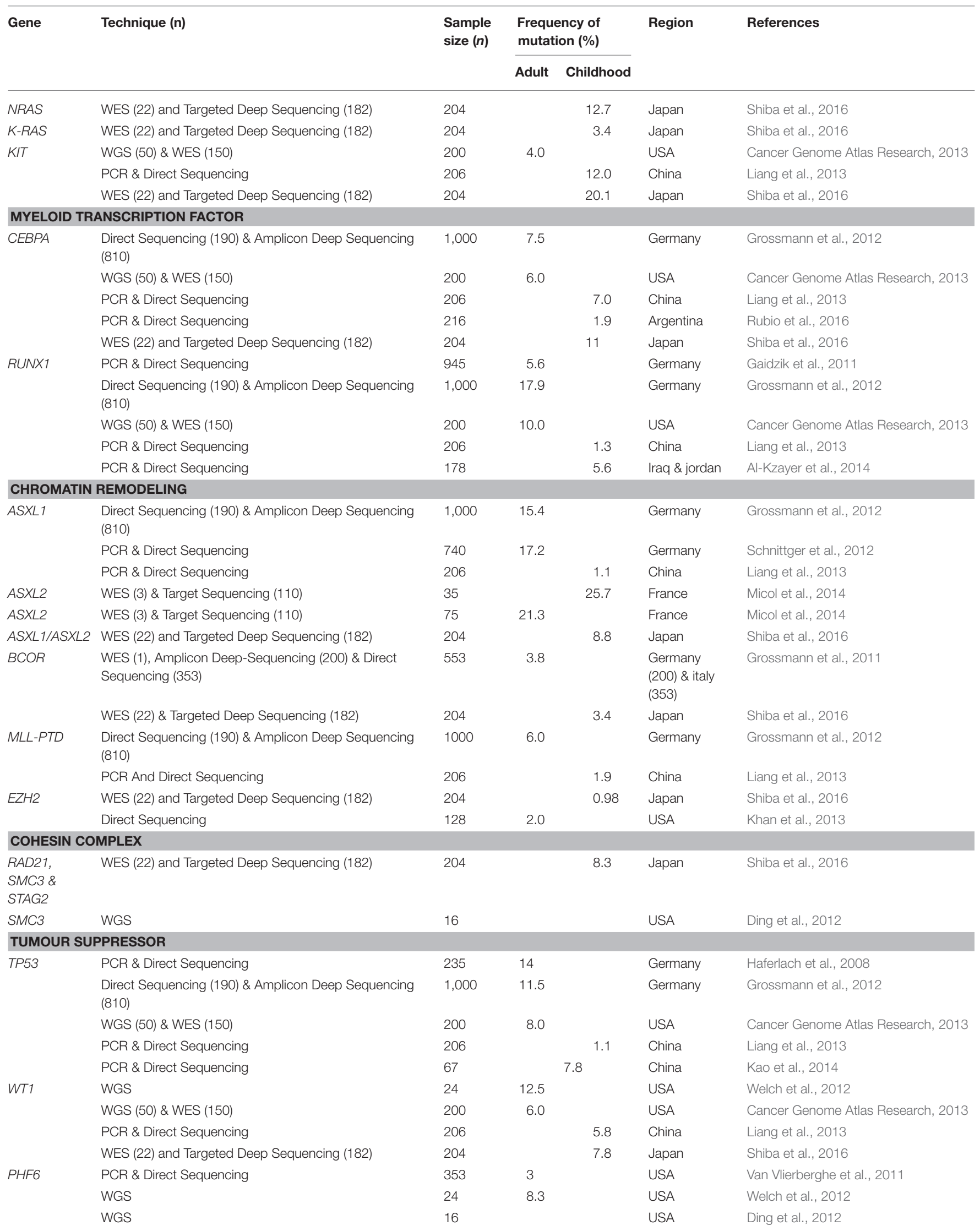


TABLE 2 | Prognostic impact of mutated gene in AML.

\begin{tabular}{|c|c|c|}
\hline Gene & Prognostic impact & References \\
\hline NPMI & Favorable prognosis with a reduced risk of relapse & Döhner et al., 2005; Papaemmanuil et al., 2016 \\
\hline DNMT3A & $\begin{array}{l}\text { Unfavorable outcomes and higher relapse rates } \\
\text { Worse prognosis was observed in } \mathrm{CN} \text {-AML patients }\end{array}$ & $\begin{array}{l}\text { Marková et al., 2012; Patel et al., 2012; Shivarov et al., 2013; Tie } \\
\text { et al., } 2014\end{array}$ \\
\hline$I D H 1$ and $I D H 2$ & $\begin{array}{l}\text { Unfavorable outcomes in patients with IDH1 mutations compared } \\
\text { to with IDH2 mutations } \\
\text { Shorter relapse free survival in patients with double positive IDH } \\
\text { and IDH and NPM1 mutations, but FLT3-ITD-negative }\end{array}$ & $\begin{array}{l}\text { Abbas et al., 2010; Paschka et al., 2010; Patel et al., 2012; Aref } \\
\text { et al., } 2015\end{array}$ \\
\hline TET2 & The prognostic effect remains controversial. & $\begin{array}{l}\text { Gaidzik et al., 2012; Patel et al., 2012; Ahn et al., 2015; Kutny } \\
\text { et al., } 2015\end{array}$ \\
\hline FLT3-ITD & Poor outcomes and high relapse rate & $\begin{array}{l}\text { Kottaridis et al., 2002; Shih et al., 2002; Cloos et al., 2006; } \\
\text { Alvarado et al., } 2014\end{array}$ \\
\hline FLT3-TKD & Prognosis value remains unclear and contradicting & Martelli et al., 2013; Ofran and Rowe, 2013 \\
\hline NRAS & $\begin{array}{l}\text { No difference outcomes in patients with mutant and wild-type } \\
\text { NRAS }\end{array}$ & Bowen et al., 2005; Bacher et al., 2006; Berman et al., 2011 \\
\hline KIT & $\begin{array}{l}\text { Conferred increased relapse risk in adult CBF-AML with } t(8 ; 21) \text { but } \\
\text { no significant impact on childhood CBF-AML patients }\end{array}$ & Pollard et al., 2010; Chen et al., 2016 \\
\hline CEBPA & $\begin{array}{l}\text { Good prognosis marker with significant longer relapse free overall } \\
\text { survival especially in } \mathrm{CN}-\mathrm{AML} \\
\text { Prolonged survival after relapse if patients acquired CEBPA } \\
\text { mutation during relapse }\end{array}$ & $\begin{array}{l}\text { Renneville et al., 2009a; Pastore et al., 2014; Li et al., 2015; } \\
\text { Tawana et al., } 2015\end{array}$ \\
\hline RUNX1 & $\begin{array}{l}\text { Unfavorable outcome, predictive of chemotherapy resistance and } \\
\text { increased relapse rate }\end{array}$ & Gaidzik et al., 2011; Grossmann et al., 2012; Ismael et al., 2014 \\
\hline$A S X L 1$ and $A S X L 2$ & $\begin{array}{l}\text { Predictive of inferior prognosis specifically to male adults with } \\
\text { MDS, age and positive RUNX1 mutations } \\
\text { Prognostic implication remains inconclusive in childhood AML }\end{array}$ & $\begin{array}{l}\text { Schnittger et al., 2012; Micol et al., 2014; Döhner et al., 2015; } \\
\text { Shiba et al., } 2016\end{array}$ \\
\hline$B C O R$ & $\begin{array}{l}\text { Associated with poorer prognosis in adult } \mathrm{AML} \\
\text { Similar } 3 \text {-year overall survival in childhood } \mathrm{AML} \text { with or without } \\
\text { BCOR mutation }\end{array}$ & Grossmann et al., 2011; Shiba et al., 2016 \\
\hline KMT2A/MLL-PTD & $\begin{array}{l}\text { Conferred an inferior prognosis, especially those with CN-AML } \\
\text { Worst prognosis in patients with double positive IDH and DNMT3A } \\
\text { mutations }\end{array}$ & Döhner et al., 2002; Grossmann et al., 2012; Kao et al., 2015 \\
\hline$E Z H 2$ & Poor prognosis and inferior survival & Kawahara et al., 2012; Larsson et al., 2014 \\
\hline SMC3, RAD21 and STAG2 & No association between the mutations and overall survival rate & Shiba et al., 2016 \\
\hline TP53 & $\begin{array}{l}\text { Associated with inferior prognosis and higher relapse risk, the } \\
\text { worst prognosis in AML }\end{array}$ & Grossmann et al., 2012; Hou et al., 2015 \\
\hline WT1 & $\begin{array}{l}\text { Adverse outcomes in both childhood and adult AML, low overall } \\
\text { survival rate and high relapse rate }\end{array}$ & Hollink et al., 2009; Renneville et al., 2009b; Hou et al., 2010 \\
\hline PHF6 & $\begin{array}{l}\text { Poor outcomes in intermediate risk group AML patients } \\
\text { Predictive biomarker for relapse SMC3relapse }\end{array}$ & Ding et al., 2012; Patel et al., 2012 \\
\hline
\end{tabular}

rate (Alvarado et al., 2014). Recently, some studies showed that patients with FLT3-ITD AML should be offered allogeneic stem cell transplant when feasible as the preferred post-remission treatment for better survival outcomes (Ho et al., 2016; Oran et al., 2016). Meanwhile, mutations in FLT3-TKD appeared to be less commonly detected and its prognosis value remains unclear and contradicting (Martelli et al., 2013; Ofran and Rowe, 2013).

Neuroblastoma RAS Viral (v-ras) Oncogene Homolog (NRAS) and Kirsten Rat Sarcoma Viral Oncogene Homolog (KRAS) belong to the RAS GTPase family that encode a membrane-associated guanosine nucleotide phosphate (GTP) binding proteins, and are involved in regulating signal transduction upon binding of ligand to a variety of membrane receptors (Bowen et al., 2005; Berman et al., 2011). The occurrence of NRAS mutations has been reported among adult (9-12\%) and childhood AML (12-13\%) but KRAS mutations appeared to be more prevalent in adult AML than childhood AML (12 vs. 3-7\%) (Mardis et al., 2009; Cancer Genome Atlas Research, 2013; Liang et al., 2013; Kao et al., 2014; Shiba et al., 2016). Larger cohort studies have shown that the clinical outcomes of patients who harbored mutant and wild-type NRAS did not differ, as evidenced by similar complete remission (Bowen et al., 2005; Bacher et al., 2006; Berman et al., 2011) and relapse rates (Bowen et al., 2005; Bacher et al., 2006; Berman et al., 2011).

Proto-Oncogene Receptor Tyrosine Kinase (KIT) is involved in hematopoiesis as well as proliferation and regulation of cell survival. The frequency of KIT mutation in adult AML was reported lower as compared to childhood AML (4 vs. 12-20\%) (Cancer Genome Atlas Research, 2013; Liang et al., 2013; Shiba et al., 2016). A higher frequency was reported in core-binding factor acute myeloid leukemia (CBF-AML) with $\operatorname{inv}(16)$ and 
$\mathrm{t}(8 ; 21)$, in both children (19-44\%) and adults (16-46\%) (Jones et al., 2010; Pollard et al., 2010). Based on the meta-analysis conducted by Chen et al. KIT mutations conferred increased relapse risk in adult CBF-AML with $\mathrm{t}(8 ; 21)$ (Chen et al., 2016). In contrast, KIT mutations did not show significant impact on relapse risk in childhood CBF-AML patients (Pollard et al., 2010). In vitro studies demonstrated that the use of a tyrosine kinase inhibitor was effective against leukemic cells harboring KIT mutations and served as promising therapeutic approach for AML patients.

\section{Myeloid Transcription Factor}

CCAAT Enhancer Binding Protein Alpha (CEBPA) is a transcription factor that is involved in regulating the differentiation of neutrophils. CEBPA mutations were mostly located at the N-terminal domain (NTD) and bZip domain (Ho et al., 2009). The frequency of CEBPA mutations reported in childhood AML is generally double that seen in adult AML (2-12 vs. 6-7.5\%) (Grossmann et al., 2012; Cancer Genome Atlas Research, 2013; Liang et al., 2013; Rubio et al., 2016; Shiba et al., 2016). Biallelic CEBPA mutations are associated with favorable prognosis in CN-AML whilst monoallelic mutations showed contradicting outcomes in patients (Pastore et al., 2014; Li et al., 2015). Several lines of evidence have shown that the CEBPA mutation served as a good prognosis marker of AML in which patients with CEBPA mutation had significantly longer relapse free overall survival (Renneville et al., 2009a). More strikingly, patients who acquired CEBPA mutation during relapse (absent in diagnostic sample) had favorable outcomes with prolonged survival after relapse, with a $67 \%$ 10-year overall survival rate (Tawana et al., 2015).

Runt Related Transcription Factor (RUNX1) encodes for a core-binding factor which binds to the core element of many enhancers and promoters. RUNX1 mutations are more prevalent in AML without complex karyotype, with $5-18 \%$ in adult AML (Gaidzik et al., 2011; Grossmann et al., 2012; Cancer Genome Atlas Research, 2013) and 1-6\% in childhood AML (Liang et al., 2013; Al-Kzayer et al., 2014). RUNX1 mutation is associated with unfavorable outcome, is predictive of chemotherapy resistance with a refractory rate of $30 \%$ and also an increased relapse rate (Gaidzik et al., 2011; Grossmann et al., 2012). Clonal evolution of RUNX1 mutation was reported in the relapsed samples of childhood AML cases (Ismael et al., 2014). Clinical analysis has proven that patients with RUNX1 mutations who received allogeneic HSCT had a 52\% 4-year relapse free survival as compared to those treated with conventional intensive postremission therapy ( $0 \%$ 4-year relapse free survival) (Gaidzik et al., 2011). Hence, allogeneic hematopoietic stem cell transplant (HSCT) is highly recommended for patients harboring RUNX1 mutation as compared to conventional consolidation therapy.

\section{Chromatin Remodeling}

Additional Sex Combs Like 1 Transcriptional Regulator (ASXL1) and Additional Sex Combs Like 2 Transcriptional Regulator (ASXL2) encodes a dual-function chromatin-binding protein, which acts as a transcription activator or repressor (Katoh and Katoh, 2003). ASXL1 mutation is frequently associated with secondary AML evolving from myelodysplastic syndrome (MDS) (Devillier et al., 2012) with a 5-17\% occurrence in adult AML, with a higher frequency in cases with intermediate risk cytogenetics (31\%) and CN-AML (13\%) (Grossmann et al., 2012; Schnittger et al., 2012; Döhner et al., 2015). The incidence of ASXL1 mutation is rare (1\%) in childhood AML and increases with age (Liang et al., 2013). However, the prevalence of ASXL2 mutation in both adult (22\%) and childhood (26\%) AML is almost similar (Micol et al., 2014). In childhood AML, the prognostic implication of ASXL1 and ASXL2 mutations remains inconclusive. Shiba et al. (2016) did not observe the association with inferior outcome, whilst Micol et al. (2014) reported that the mutations were associated with increased relapse risk. Thus, a larger study cohort is needed to confirm the prognostic effect of ASXL1 and ASXL2 in childhood AML. Meanwhile, ASXL1 mutations were predictive of inferior prognosis and contributed significantly to leukemogenesis in male adults with AML with MDS, those older in age and those harboring RUNX1 mutations (Schnittger et al., 2012; Döhner et al., 2015).

BCL6 Corepressor (BCOR) encodes a POZ/zinc finger transcriptional repressor (Huynh et al., 2000), and its loss-offunction mutation has led to the inhibition of proliferation and differentiation of myeloid cells (Cao et al., 2016). The occurrence rate of $B C O R$ mutation in both childhood and adult AML was found to be almost similar, namely 3.4 and 3.8\% (Grossmann et al., 2011; Shiba et al., 2016) respectively by using the WES technique. The frequency of $B C O R$ mutations was higher in $\mathrm{CN}$ AML adult patients (17\%), and associated with poorer prognosis, with an overall 2-year survival rate of $25.6 \%$ (Grossmann et al., 2011). In contrast, the 3 -year overall survival was similar for childhood AML patients with or without BCOR mutation (71 vs. 72\%) (Shiba et al., 2016).

Lysine (K) Methyltransferase 2A (KMT2A) or formerly known as Mixed-Lineage Leukemia $(M L L)$ is involved in regulating gene expression during early development and hematopoiesis. $M L L$ PTD was found mutated in $6 \%$ of adult AML patients (Döhner et al., 2002; Grossmann et al., 2012) and a lower frequency of MLL-PTD (2\%) was reported in childhood AML (Liang et al., 2013). MLL-PTD conferred an inferior prognosis, in which the 3 year event free survival was only 10.5\% (Grossmann et al., 2012), and $69 \%$ of CN-AML patients with MLL-PTD relapsed after achieving remission (Döhner et al., 2002). Therefore, MLL-PTD is associated with inferior outcomes in AML patients especially those with CN-AML. In addition, inferior event free survival (median 0 vs. 6.8 months) was noted in $M L L$-PTD AML patients with DNMT3A mutations compared to those without DNMT3A mutations (Kao et al., 2015).

Enhancer of Zeste Homologue 2 (EZH2) is a histone methyltransferase which is involved in transcriptional repression by depositing histone $\mathrm{H} 3$ lysine 27 (H3K27) and also plays a pivotal role in hematopoiesis (Yap et al., 2011; Lund et al., 2014). EZH2 controls the balance between cell differentiation and renewal, thus its dysregulation may lead to tumorigenesis (Lund et al., 2014). EZH2 mutations decreased H3K27 trimethylation and increased chromatin relaxation. EZH2 mutations have been detected in $\sim 2 \%$ adult AML (Khan et al., 2013) and $\sim 1 \%$ childhood AML (Shiba et al., 2016). EZH2 mutation was 
more frequently detected in acute megakaryoblastic leukemia (AMKL) and AMKL with Down Syndrome (DS-AMKL), 16 and 33\% respectively (Yoshida et al., 2013). EZH2 mutations was correlated with poor prognosis and inferior survival (Kawahara et al., 2012; Larsson et al., 2014). 3-Deazaneplanocin (DZNep), an EZH2 inhibitor, may serve as a potential drug for consolidation or maintenance therapy in AML patients to decrease the chance of relapse by eliminating the cancer stem cells which are resistant to conventional chemotherapy such as cytarabine and daunorubicin (Miranda et al., 2009; Horton and Huntly, 2012).

\section{Cohesin Complex}

Cohesin is a multiprotein complex which comprises of four primary subunits SMC1A, SMC3, RAD21, and STAG1/STAG2, and is responsible for sister chromatid cohesion, gene expression regulation and DNA repair (Haarhuis et al., 2014; Kim et al., 2016). SMC3 gene mutation was first described by Ding et al. (2012) by comparing the genomic landscape of a primary and matched relapse adult AML using WGS. The SMC3 mutation was found enriched in relapsed clones and may be induced by the damaging effects from cytotoxic chemotherapy. Subsequently, in 2016, Shiba et al. reported that SMC3, RAD21, and STAG2 mutations were detected in $8.3 \%$ of 204 childhood AML cases, and the truncating mutations resulted in loss of cohesin function. However, they did not observe an association between the mutations and overall survival rate (Shiba et al., 2016). A larger cohort is therefore needed to provide a better overview of the utility of cohesin as a prognostic biomarker.

\section{Tumor Suppressor}

Tumor Protein p53 (TP53), is the most well-studied tumor suppressor gene and is involved in cell cycle regulation in response to cellular stress. TP53 is frequently mutated in AML patients with complex karyotypes, with an incidence rate of 69-73\% (Haferlach et al., 2008; Grossmann et al., 2012). The incidence rate was reported lower in other cytogenetic subgroups, ranging from 8 to $14 \%$ in adult AML and about $1 \%$ in childhood AML (Haferlach et al., 2008; Grossmann et al., 2012; Cancer Genome Atlas Research, 2013; Liang et al., 2013; Kao et al., 2014). TP53 mutation was associated with inferior prognosis and higher relapse risk, in which the 3-year overall survival and event free survival was $0 \%$ (Grossmann et al., 2012). The observation of a poorer prognosis for TP53 mutation was also independent of age, karyotype and other mutations such as NPM1/FLT3ITD, CEBPA, RUNX1, WT1, DNMT3A, and IDH2 (Hou et al., 2015). Based on above evidence, TP53 mutation may serve as a promising predictive biomarker of the worst prognosis in AML.

Wilms Tumor 1 (WT1) is a transcription factor involved in urogenital development and was found overexpressed in AML with a role in promoting leukemogenesis (Rampal and Figueroa, 2016). The frequency of WT1 mutation was slightly higher in adult AML compared to childhood AML (6-12.5 vs. 6-8\%) (Welch et al., 2012; Cancer Genome Atlas Research, 2013; Liang et al., 2013; Shiba et al., 2016). WT1 mutation was significantly correlated with adverse outcomes in both childhood and adult AML. In adult AML ( $n=268$, aged 15-50 year), the 4-year overall survival rate was only $22 \%$, and the relapse rate was relatively high (82\%) (Renneville et al., 2009b). A similar finding of higher relapse incidence (85.7\%) was reported in 470 adult AML patients with WT1 mutations (Hou et al., 2010). The similar pattern was seen in childhood AML with cumulative relapse incidence of $70 \%$ in 298 patients (Hollink et al., 2009).

Plant Homeodomain Finger 6 (PHF6) acts as a tumor suppressor gene. PHF6 non-sense and frameshift mutations have been shown to result in loss-of-function alleles (Van Vlierberghe et al., 2011). PHF6 mutations were observed in T-cell acute lymphoblastic leukemias, with an incidence rate of 20\% (Van Vlierberghe et al., 2010). In contrast, PHF6 mutations were only detected in 3-8\% adult AML (Van Vlierberghe et al., 2011; Ding et al., 2012), and more frequently detected in males than females (Van Vlierberghe et al., 2011). Adverse outcomes had been reported in AML patients with intermediate risk group (Patel et al., 2012). PHF6 mutations were found to be acquired during initiation of leukemogenesis and were also enriched in relapsed samples (Ding et al., 2012), hence could serve as a potential predictive biomarker of AML relapse.

\section{DEVELOPMENT OF TARGETED THERAPIES IN AML}

The poor prognosis for AML has been a key driver for the research and development of targeted therapies. The emerging targeted therapies for the management of AML include FLT3 inhibitors, IDH inhibitors, and MEK inhibitors. In April 2017, the new drug midostaurin (Rydapt; Novartis Pharmaceuticals, Inc) received approval by the US Food and Drug Administration (FDA) for the treatment of adult patients with newly diagnosed FLT3-mutated AML (Levis, 2017). Midostaurin (N-benzoyl staurosporine also previously known as CGP41251 and PKC412), a derivative of staurosporine, is an indolocarbazole and is a pan-kinase inhibitor, a derivative of staurosporine (Tamaoki et al., 1986). It is a kinase inhibitor against both the FLT3-ITD and FLT3TKD mutants, and relapsed/refractory patients treated with midostaurin showed great reduction in peripheral blood and marrow blasts (Stone et al., 2005; Fischer et al., 2010). Midostaurin has been approved and recommended to be given in combination with drugs for induction (cytarabine and daunorubicin) and consolidation (high-dose cytarabine) (Levis, 2017).

Another first generation FLT3 inhibitor, Lestaurtinib (previously known as CEP-701), is a relatively less selective compound compared to midostaurin, and its usage has not been able to improve the survival in FLT3 mutated AML patients (Knapper et al., 2017). The UK MRC AML15 clinical trial (ISRNCTN17161961) \& UK NCRI AML17 (ISRNCTN55675535) involving five hundred patients in the United Kingdom, Denmark, and New Zealand showed no significant differences in the 5-year overall survival and 5-year relapse-free survival when added to the standard chemotherapy for newly diagnosed FLT3 mutated AML (Knapper et al., 2017). 
This factor has contributed to the development of second generation of FLT3 inhibitors which are more potent and more selective in action.

Quizartinib (AC220) is a second generation FLT3 inhibitor that exhibits low nanomolar potency in biochemical and cellular assays, and has exceptional kinase selectivity (Zarrinkar et al., 2009). In the phase 3 clinical trial, QuANTUM-First, to test the effect of quizartinib in combination with conventional chemotherapy in FLT3/ITD patients (NCT02668653), and the QuANTUM-R trial to compare quizartinib monotherapy vs. conventional salvage therapies among relapsed/refractory FLT3ITD mutated patients (NCT02039726), the results showed a higher composite complete remission $(\mathrm{CRc})$ rate in both older and younger patients with FLT3-ITD mutated relapsed/refractory AML (Stein and Tallman, 2016; Fathi and Chen, 2017; Saygin and Carraway, 2017). Another selective FLT3 inhibitor that has been tested in a phase 3 clinical trial is Gliteritinib. Gilteritinib (previously referred to as ASP2215) is a pyrazinecarboxamide derivative, with activity against both FLT3-ITD and FLT3-TKD mutations (Lee et al., 2017). Remarkable results were obtained in terms of the CRc among patients with FLT3ITD and FLT3-TKD mutations (Perl et al., 2017) and also in the ongoing phase 3 clinical trial to test gilteritinib vs. salvage chemotherapy in relapsed/refractory FLT3 mutated AML (NCT02421939).

The limiting factor for these second generation FLT3 inhibitors was the short duration of response as shown with quizartinib (3 months) and gilteritinib (5 months) (Saygin and Carraway, 2017). In addition, there have been reports on resistance to quizartinib, which was shown to be attributed by the mutations in the TKD of the FLT3 gene (Moore et al., 2012; Smith et al., 2012). Crenolanib, a highly selective and potent nextgeneration FLT3 inhibitor, can overcome quizartinib resistance by targetting both FLT3-ITD mutants and the FLT3-D835 point mutants (Galanis et al., 2014). This drug is currently in a phase 3 clinical trial, to test the effect in combination with salvage chemotherapy for relapsed or refractory FLT3 mutated AML patients (NCT02298166) (Levis, 2017).

Another major breakthrough in the treatment of AML is the approval of enasidenib by the FDA in early August 2017. Enasidenib is approved for the treatment of relapsed or refractory in IDH2 mutated adult AML patients. Enasidenib (AG-221/CC90007) is a first-in-class, oral, selective inhibitor of mutant-IDH2 enzymes and assessment outcomes in the largest relapsed or

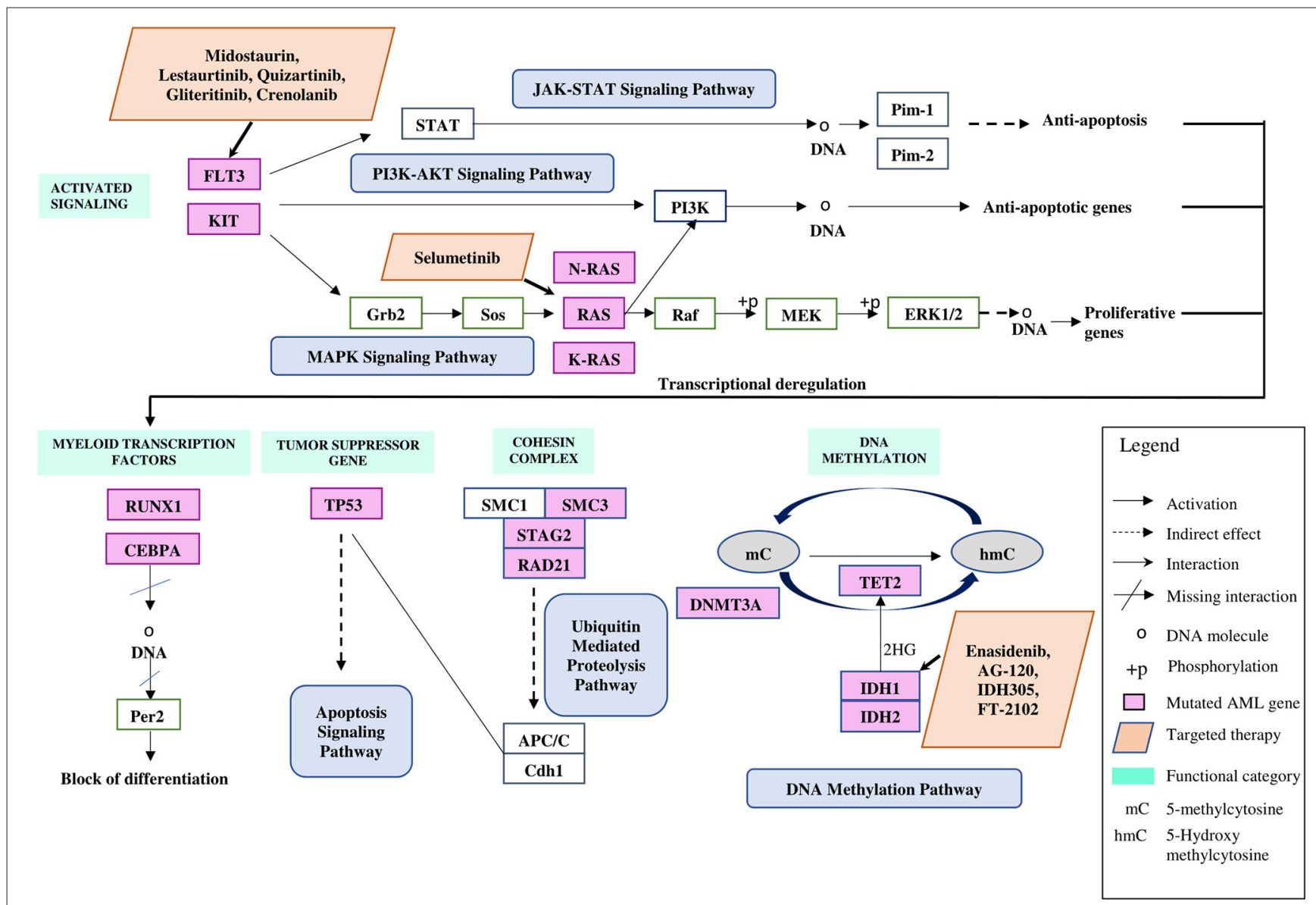

FIGURE 1 | Commonly mutated genes in both childhood and adult AML illustrated based on functional categories, in relation to pathways involved with targeted therapies. Figure was adapted and modified from Kanehisa et al. (2016) and Döhner et al. (2015). 
refractory mutant-IDH2 AML patient shows a $40.3 \%$ overall response rate with 9.3 months median overall survival, and 19.7 months overall survival for those who attained complete remission (Stein et al., 2017). Meanwhile, other oral inhibitors such as AG-120, IDH305, and FT-2102 are currently being evaluated in AML patients with IDH1 mutation. Early results of ongoing clinical trials for the AG-120 ((NCT02074839) and IDH305 (NCT02381886) in relapsed or refractory AML patient showed that both drugs were well-tolerated and the overall response rate was 36 and 33\% respectively (Birendra and DiNardo, 2016; Saygin and Carraway, 2017). Therefore, these IDH1 inhibitors seem promising as targeted therapies for AML.

MAP-ERK kinase (MEK) inhibitor has been used in RAS mutated AML patients. Selumetinib (AZD6244, ARRY-142886) is a potent and selective small-molecule inhibitor of MEK (Yeh et al., 2007; Adjei et al., 2008). The phase II study of oral selumetinib showed hematologic improvement in platelets count as well as reduction in the bone marrow blasts percentage in AML patients with KRAS mutation (Jain et al., 2014). Interestingly, the use of this MEK inhibitor also resulted in good response and disease stabilization in patients with KIT mutation (rs3733542 in exon 18) but require further validation (Jain et al., 2014). The favorable effect of selumetinib makes this MEK inhibitor a good potential in targeting the RAS mutation in AML patients.

The emergence of these molecular targeted therapies has contributed to the improvement in the treatment of AML patients specifically resulting in better response rate and overall outcomes, with less toxicity than standard cytotoxic therapy. The molecular targeted therapies for the management of AML as discussed in this review are illustrated in Figure $\mathbf{1}$ and Table 3.

\section{CONCLUSION}

The breakthrough in genomic technologies, especially NGS, has enhanced our understanding about the genetic landscape of $\mathrm{AML}$, and has led to the discovery of a long list of mutations which are potentially useful as prognostic markers of AML. Interestingly, the prognostic impact of the genetic events from the same functional categories are rather varied. For instance, the presence of NPMI, IDH2, and CEBPA mutations predicted a favorable prognosis whilst KRAS and NRAS mutations had little clinical impact. Also, mutations in DNMT3A, IDH1, TET2, FLT3 $I T D, M L L$, and $E Z H 2$ are associated with poorer prognosis, whilst mutations in RUNX1, WT1, and TP53 are predictive of the worst outcomes and increased relapse risk in both adult and childhood AML. Meanwhile, the prognostic impact of KIT, ASXL1/ASXL2, and $B C O R$ mutations between adult and childhood AML showed a contradiction. The implications of FLT3-TKD, SMC3, RAD21, STAG2, and PHF6 mutations in AML remain unclear and their usefulness as predictive biomarkers of relapse warrants further investigations. Taken together, gene mutations provide additional valuable clinical information which could help to refine the risk or prognostic classification of AML and to guide risk-adapted therapies. Discovery of gene mutations which are uniquely acquired or enriched in relapse AML may pave new ways toward the development of novel therapeutic therapies and precision medicine for AML.

TABLE 3 | Targeted therapies in AML.

\begin{tabular}{|c|c|c|c|c|}
\hline Gene & Drugs & Status & Single/Combination & References \\
\hline \multirow[t]{6}{*}{ FLT3-ITD/FLT3-TKD } & $\begin{array}{l}\text { Midostaurin } \\
\text { (CGP41251/PKC412) }\end{array}$ & $\begin{array}{l}\text { FDA Approved (Rydapt; Novartis } \\
\text { Pharmaceuticals, Inc) }\end{array}$ & $\begin{array}{l}\text { In combination with induction and } \\
\text { consolidation chemotherapy }\end{array}$ & Levis, 2017 \\
\hline & Lestaurtinib (CEP-701) & $\begin{array}{l}\text { Phase } 3 \text { Clinical Trial UK MRC AML15 } \\
\text { (ISRNCTN17161961) \& UK NCRI } \\
\text { AML17 (ISRNCTN55675535) }\end{array}$ & $\begin{array}{l}\text { In combination with induction and } \\
\text { consolidation chemotherapy }\end{array}$ & Knapper et al., 2017 \\
\hline & Quizartinib (AC220) & $\begin{array}{l}\text { Phase } 3 \text { Clinical Trial QuANTUM-First } \\
\text { (NCT02668653) }\end{array}$ & $\begin{array}{l}\text { In combination with induction and } \\
\text { consolidation chemotherapy }\end{array}$ & $\begin{array}{l}\text { Stein and Tallman, 2016; Fathi } \\
\text { and Chen, 2017; Saygin and } \\
\text { Carraway, } 2017\end{array}$ \\
\hline & & $\begin{array}{l}\text { Phase } 3 \text { Clinical Trial QuANTUM-R } \\
\text { (NCT02039726) }\end{array}$ & Single agent & \\
\hline & Gliteritinib (ASP2215) & Phase 3 Clinical Trial (NCT02421939) & Single agent & Lee et al., 2017; Perl et al., 2017 \\
\hline & Crenolanib & Phase 3 Clinical Trial (NCT02298166) & $\begin{array}{l}\text { In combination with salvage } \\
\text { chemotherapy }\end{array}$ & Galanis et al., 2014; Levis, 2017 \\
\hline IDH2 & $\begin{array}{l}\text { Enasidenib } \\
\text { (AG-221/CC-90007) }\end{array}$ & $\begin{array}{l}\text { (Idhifa) FDA Approved (Celgene } \\
\text { Corporation) }\end{array}$ & Single agent & Stein et al., 2017 \\
\hline \multirow[t]{3}{*}{ IDH1 } & AG-120 & Phase 1 Clinical Trial (NCT02074839) & Single agent & Birendra and DiNardo, 2016 \\
\hline & IDH305 & Phase 1 Clinical Trial (NCT02381886) & $\begin{array}{l}\text { In combination with induction and } \\
\text { consolidation chemotherapy }\end{array}$ & $\begin{array}{l}\text { Stein and Tallman, 2016; Saygin } \\
\text { and Carraway, } 2017\end{array}$ \\
\hline & FT-2102 & $\begin{array}{l}\text { Phase 1/1b Clinical Trial } \\
\text { (NCT02719574) }\end{array}$ & In combination with azacitidine & \\
\hline
\end{tabular}

$\begin{array}{ll}\text { RAS Selumetinib (AZD6244, Phase II Consortium (Chicago, IL) I } \quad \text { Single agent } & \text { ARRY-142886) }\end{array}$




\section{AUTHOR CONTRIBUTIONS}

HAz drafted this manuscript. CP, HAl, N-SA, and RJ involved in the critical evaluation of the manuscript.

\section{REFERENCES}

Ab Manan, A., Ibrahim Tamin, N. S., Abdullah, N. H., Zainal Abidin, A., and Wahab, M. (2016). Malaysia Cancer Statistics, Data And Figure. Malaysian National Cancer Registry Report 2007-2011.

Abbas, S., Lugthart, S., Kavelaars, F. G., Schelen, A., Koenders, J. E., Zeilemaker, A., et al. (2010). Acquired mutations in the genes encoding IDH1 and IDH2 both are recurrent aberrations in acute myeloid leukemia : prevalence and prognostic value Blood 116, 2122-2126. doi: 10.1182/blood-2009-11-250878

Adjei, A. A., Cohen, R. B., Franklin, W., Morris, C., Wilson, D., Molina, J. R., et al. (2008). Phase I pharmacokinetic and pharmacodynamic study of the oral, small-molecule mitogen-activated protein kinase kinase 1 / 2 inhibitor AZD6244 (ARRY-142886) in patients with advanced cancers. J. Clin. Oncol. 26, 2139-2146. doi: 10.1200/JCO.2007.14.4956

Ahn, J. S., Kim, H. J., Kim, Y. K., Jung, S. H., Yang, D. H., Lee, J. J., et al. (2015). Adverse prognostic effect of homozygous TET2 mutation on the relapse risk of acute myeloid leukemia in patients of normal karyotype. Haematologica 100, 351-353. doi: 10.3324/haematol.2015.126227

Al-Kzayer, L. F., Sakashita, K., Al-Jadiry, M. F., Al-Hadad, S. A., Uyen le, T. N., Liu, T., et al. (2014). Frequent coexistence of RAS mutations in RUNX1-mutated acute myeloid leukemia in Arab Asian children. Pediatr. Blood Cancer 61, 1980-1985. doi: 10.1002/pbc.25151

Alvarado, Y., Kantarjian, H. M., Luthra, R., Ravandi, F., Borthakur, G., GarciaManero, G., et al. (2014). Treatment with FLT3 inhibitor in patients with FLT3-mutated acute myeloid leukemia is associated with development of secondary FLT3-tyrosine kinase domain mutations. Cancer 120, 2142-2149. doi: $10.1002 / \mathrm{cncr} .28705$

Andersson, A. K., Miller, D. W., Lynch, J. A., Lemoff, A. S., Cai, Z., Pounds, S. B., et al. (2011). IDH1 and IDH2 mutations in pediatric acute leukemia. Leukemia 25, 1570-1577. doi: 10.1038/leu.2011.133

Aref, S., Kamel Areida el, S., Abdel Aaal, M. F., Adam, O. M., El-Ghonemy, M. S., El-Baiomy, M. A., et al. (2015). Prevalence and clinical effect of IDH1 and IDH2 mutations among cytogenetically normal acute myeloid leukemia patients. Clin. Lymphoma Myeloma Leuk. 15, 550-555. doi: 10.1016/j.clml.2015.05.009

Aslanyan, M. G., Kroeze, L. I., Langemeijer, S. M. C., Koorenhof-Scheele, T. N., Massop, M., Van Hoogen, P., et al. (2014). Clinical and biological impact of TET2 mutations and expression in younger adult AML patients treated within the EORTC/GIMEMA AML-12 clinical trial. Ann. Hematol. 93, 1401-1412. doi: 10.1007/s00277-014-2055-7

Bacher, U., Haferlach, T., Schoch, C., Kern, W., and Schnittger, S. (2006). Implications of NRAS mutations in AML: a study of 2502 patients. Blood 107, 3847-3853. doi: 10.1182/blood-2005-08-3522

Berman, J. N., Gerbing, R. B., Alonzo, T. A., Ho, P. A., Miller, K., Hurwitz, C., et al. (2011). Prevalence and clinical implications of NRAS mutations in childhood AML: a report from the Children's Oncology Group. Leukemia 25, 1039-1042. doi: $10.1038 /$ leu.2011.31

Birendra, K., and DiNardo, C. D. (2016). Evidence for clinical differentiation and differentiation syndrome in patients with acute myeloid leukemia and IDH1 mutations treated with the targeted mutant IDH1 inhibitor, AG-120. Clin. Lymphoma Myeloma Leuk. 16, 460-465. doi: 10.1016/j.clml.2016.04.006

Bowen, D. T., Frew, M. E., Hills, R., Gale, R. E., Wheatley, K., Groves, M. J., et al. (2005). RAS mutation in acute myeloid leukemia is associated with distinct cytogenetic subgroups but does not influence outcome in patients younger than 60 years. Blood 106, 2113-2119. doi: 10.1182/blood-2005-03-0867

Brown, P., McIntyre, E., Rau, R., Meshinchi, S., Lacayo, N., Dahl, G., et al. (2007). The incidence and clinical significance of nucleophosmin mutations in childhood AML. Blood 110, 979-985. doi: 10.1182/blood-2007-02-076604

Cancer Genome Atlas Research, N. (2013). Genomic and epigenomic landscapes of adult de novo acute myeloid leukemia. N. Engl. J. Med. 368, 2059-2074. doi: 10.1056/NEJMoa1301689

\section{FUNDING}

This study is funded by Universiti Kebangsaan Malaysia Research Grant (Dana Impak Perdana DIP-2014-036).

Cao, Q., Gearhart, M. D., Gery, S., Shojaee, S., Yang, H., Sun, H., et al. (2016). BCOR regulates myeloid cell proliferation and differentiation. Leukemia 30, 1155-1165. doi: 10.1038/leu.2016.2

Chen, W., Xie, H., Wang, H., Chen, L., Sun, Y., Chen, Z., et al. (2016). Prognostic significance of KIT mutations in core-binding factor acute myeloid leukemia: a systematic review and meta-analysis. PLOS ONE 11:e0146614. doi: 10.1371/journal.pone.0146614

Cloos, J., Goemans, B. F., Hess, C. J., van Oostveen, J. W., Waisfisz, Q., Corthals, S., et al. (2006). Stability and prognostic influence of FLT3 mutations in paired initial and relapsed AML samples. Leukemia 20, 1217-1220.doi: 10.1038/sj.leu.2404246

Creutzig, U., Van Den Heuvel-Eibrink, M. M., Gibson, B., Dworzak, M. N., Adachi, S., De Bont, E., et al. (2012). Diagnosis and management of acute myeloid leukemia in children and adolescents: recommendations from an international expert panel. Blood 120, 3187-3205. doi: 10.1182/blood-2012-03-3 62608

Creutzig, U., Zimmermann, M., Dworzak, M. N., Gibson, B., Tamminga, R., Abrahamsson, J., et al. (2014). The prognostic significance of early treatment response in pediatric relapsed acute myeloid leukemia: results of the international study relapsed AML 2001/01. Haematologica 99, 1472-1478. doi: 10.3324/haematol.2014.104182

Damm, F., Bunke, T., Thol, F., Markus, B., Wagner, K., Gohring, G., et al. (2012). Prognostic implications and molecular associations of NADH dehydrogenase subunit 4 (ND4) mutations in acute myeloid leukemia. Leukemia 26, 289-295. doi: $10.1038 /$ leu.2011.200

Damm, F., Thol, F., Hollink, I., Zimmermann, M., Reinhardt, K., van den HeuvelEibrink, M. M., et al. (2011). Prevalence and prognostic value of IDH1 and IDH2 mutations in childhood AML: a study of the AML-BFM and DCOG study groups. Leukemia 25, 1704-1710. doi: 10.1038/leu.2011.142

De Kouchkovsky, I., and Abdul-Hay, M. (2016). Acute myeloid leukemia: a comprehensive review and 2016 update. Blood Cancer J. 6:e441. doi: 10.1038/bcj.2016.50

Devillier, R., Gelsi-Boyer, V., Brecqueville, M., Carbuccia, N., Murati, A., Vey, N., et al. (2012). Acute myeloid leukemia with myelodysplasia-related changes are characterized by a specific molecular pattern with high frequency of ASXL1 mutations. Am. J. Hematol. 87, 659-662. doi: 10.1002/ajh.23211

Ding, L., Ley, T. J., Larson, D. E., Miller, C. A., Koboldt, D. C., Welch, J. S., et al. (2012). Clonal evolution in relapsed acute myeloid leukaemia revealed by whole-genome sequencing. Nature 481, 506-510. doi: 10.1038/nature10738

Döhner, H., Estey, E. H., Amadori, S., Appelbaum, F. R., Büchner, T., Burnett, A. K., et al. (2010). Diagnosis and management of acute myeloid leukemia in adults: recommendations from an international expert panel, on behalf of the European LeukemiaNet. Blood 115, 453-474. doi: 10.1182/blood-2009-07-235358

Döhner, H., Weisdorf, D. J., and Bloomfield, C. D. (2015). Acute myeloid leukemia. N. Engl. J. Med. 373, 1136-1152. doi: 10.1056/NEJMra1406184

Döhner, K., Schlenk, R. F., Habdank, M., Scholl, C., Rucker, F. G., Corbacioglu, A., et al. (2005). Mutant nucleophosmin (NPM1) predicts favorable prognosis in younger adults with acute myeloid leukemia and normal cytogenetics: interaction with other gene mutations. Blood 106, 3740-3746. doi: 10.1182/blood-2005-05-2164

Döhner, K., Tobis, K., Ulrich, R., Fröhling, S., Benner, A., Schlenk, R. F., et al. (2002). Prognostic significance of partial tandem duplications of the MLL gene in adult patients 16 to 60 years old with acute myeloid leukemia and normal cytogenetics: a study of the acute myeloid leukemia study group Ulm. J. Clin. Oncol. 20, 3254-3261. doi: 10.1200/JCO.2002.09.088

Falini, B., Albiero, E., Bolli, N., De Marco, M. F., Madeo, D., Martelli, M., et al. (2007). Aberrant cytoplasmic expression of C-terminal-truncated NPM leukaemic mutant is dictated by tryptophans loss and a new NES motif. Leukemia 21, 2052-2054. doi: 10.1038/sj.leu.2404839 
Fathi, A. T., and Chen, Y. B. (2017). The role of FLT3 inhibitors in the treatment of FLT3-mutated acute myeloid leukemia. Eur. J. Haematol. 98, 330-336. doi: 10.1111/ejh.12841

Fischer, T., Stone, R. M., Deangelo, D. J., Galinsky, I., Estey, E., Lanza, C., et al. (2010). Phase IIB trial of oral Midostaurin (PKC412), the FMS-like tyrosine kinase 3 receptor (FLT3) and multi-targeted kinase inhibitor, in patients with acute myeloid leukemia and high-risk myelodysplastic syndrome with either wild-type or mutated FLT3. J. Clin. Oncol. 28, 4339-4345. doi: 10.1200/JCO.2010.28.9678

Gaidzik, V. I., Bullinger, L., Schlenk, R. F., Zimmermann, A. S., Rock, J., Paschka, P., et al. (2011). RUNX1 mutations in acute myeloid leukemia: results from a comprehensive genetic and clinical analysis from the AML study group. J. Clin. Oncol. 29, 1364-1372. doi: 10.1200/JCO.2010.30.7926

Gaidzik, V. I., Paschka, P., Späth, D., Habdank, M., Köhne, C. H., Germing, U., et al. (2012). TET2 mutations in acute myeloid leukemia (AML): results from a comprehensive genetic and clinical analysis of the AML study group. J. Clin. Oncol. 30, 1350-1357. doi: 10.1200/JCO.2011.39.2886

Galanis, A., Ma, H., Rajkhowa, T., Ramachandran, A., Small, D., Cortes, J., et al. (2014). Crenolanib is a potent inhibitor of FLT3 with activity against resistance-conferring point mutants. Blood 123, 94-100. doi: 10.1182/blood-2013-10-529313

Green, C. L., Evans, C. M., Zhao, L., Hills, R. K., Burnett, A. K., Linch, D. C., et al. (2011). The prognostic significance of IDH2 mutations in AML depends on the location of the mutation. Blood 118, 409-412. doi: 10.1182/blood-2010-12-322479

Grossmann, V., Schnittger, S., Kohlmann, A., Eder, C., Roller, A., Dicker, F., et al. (2012). A novel hierarchical prognostic model of AML solely based on molecular mutations. Blood 120, 2963-2972. doi: 10.1182/blood-2012-03-419622

Grossmann, V., Tiacci, E., Holmes, A. B., Kohlmann, A., Martelli, M. P., Kern, W., et al. (2011). Whole-exome sequencing identifies somatic mutations of BCOR in acute myeloid leukemia with normal karyotype. Blood 118, 6153-6163. doi: 10.1182/blood-2011-07-365320

Guzman, M. L., Li, X., Corbett, C. A., Rossi, R. M., Bushnell, T., Liesveld, J. L., et al. (2007a). Rapid and selective death of leukemia stem and progenitor cells induced by the compound 4-benzyl,2-methyl,1,2,4-thiadiazolidine,3,5-dione (TDZD-8). Blood 110, 4436-4444. doi: 10.1182/blood-2007-05-088815

Guzman, M. L., Rossi, R. M., Karnischky, L., Li, X., Peterson, D. R., Howard, D. S., et al. (2005). The sesquiterpene lactone parthenolide induces apoptosis of human acute myelogenous leukemia stem and progenitor cells. Blood 105, 4163-4169. doi: 10.1182/blood-2004-10-4135

Guzman, M. L., Rossi, R. M., Neelakantan, S., Li, X., Corbett, C. A., Hassane, D. C., et al. (2007b). An orally bioavailable parthenolide analog selectively eradicates acute myelogenous leukemia stem and progenitor cells. Blood 110, 4427-4435. doi: 10.1182/blood-2007-05-090621

Haarhuis, J. H., Elbatsh, A. M., and Rowland, B. D. (2014). Cohesin and its regulation: on the logic of X-shaped chromosomes. Dev. Cell. 31, 7-18. doi: 10.1016/j.devcel.2014.09.010

Haferlach, C., Dicker, F., Herholz, H., Schnittger, S., Kern, W., and Haferlach, T. (2008). Mutations of the TP53 gene in acute myeloid leukemia are strongly associated with a complex aberrant karyotype. Leukemia 22, 1539-1541. doi: 10.1038/leu.2008.143

Ho, A. D., Schetelig, J., Bochtler, T., Schaich, M., Schäfer-eckart, K., Hänel, M., et al. (2016). Allogeneic stem cell transplantation improves survival in patients with acute myeloid leukemia characterized by a high allelic ratio of mutant FLT3-ITD. Biol. Blood Marrow Transplant. 22, 462-469. doi: $10.1016 /$ j.bbmt.2015.10.023

Ho, P. A., Alonzo, T. A., Gerbing, R. B., Pollard, J., Stirewalt, D. L., Hurwitz, C., et al. (2009). Prevalence and prognostic implications of CEBPA mutations in pediatric acute myeloid leukemia (AML): a report from the Children's Oncology Group. Blood 113, 6558-6566. doi: 10.1182/blood-2008-10-184747

Ho, P. A., Alonzo, T. A., Kopecky, K. J., Miller, K. L., Kuhn, J., Zeng, R., et al. (2010). Molecular alterations of the IDH1 gene in AML: a Children's Oncology Group and Southwest Oncology Group study. Leukemia 24, 909-913. doi: $10.1038 /$ leu.2010.56

Ho, P. A., Kutny, M. A., Alonzo, T. A., Gerbing, R. B., Joaquin, J., Raimondi, S. C., et al. (2011). Leukemic mutations in the methylation-associated genes DNMT3A and IDH2 are rare events in pediatric AML: a report from the Children's Oncology Group. Pediatr. Blood Cancer. 57, 204-209. doi: $10.1002 / p b c .23179$

Hollink, I. H., Van Den Heuvel-Eibrink, M. M., Zimmermann, M., Balgobind, B. V., Arentsen-Peters, S. T., Alders, M., et al. (2009). Clinical relevance of Wilms tumor 1 gene mutations in childhood acute myeloid leukemia. Blood 113, 5951-5960. doi: 10.1182/blood-2008-09-177949

Horton, S. J., and Huntly, B. J. P. (2012). Recent advances in acute myeloid leukemia stem cell biology. Haematologica 97, 966-974. doi: 10.3324/haematol.2011.054734

Hou, H. A., Chou, W. C., Kuo, Y. Y., Liu, C. Y., Lin, L. I., Tseng, M. H., et al. (2015). TP53 mutations in de novo acute myeloid leukemia patients: longitudinal follow-ups show the mutation is stable during disease evolution. Blood Cancer J. 5:e331. doi: 10.1038/bcj.2015.59

Hou, H., Huang, T., Lin, L., Liu, C., Chen, C., Chou, W., et al. (2010). WT1 mutation in 470 adult patients with acute myeloid leukemia stability during disease evolution and implication of its incorporation into a survival scoring system. Blood 115, 5222-5232. doi: 10.1182/blood-2009-12-2 59390

Howlader, N., Noone, A. M., Krapcho, M., Miller, D., Bishop, K., Kosary, C. L., et al. (2017). SEER Cancer Statistics Review 1975-2014. National Cancer Institute.

Huynh, K. D., Fischle, W., Verdin, E., and Bardwell, V. J. (2000). BCoR, a novel corepressor involved in BCL-6 repression. Genes Dev. 14, 1810-1823. doi: 10.1101/gad.14.14.1810

Ibrahem, L., Mahfouz, R., Elhelw, L., Abdsalam, E. M., and Soliman, R. (2014), Prognostic significance of DNMT3A mutations in patients with acute myeloid leukemia. Blood Cells Mol. Dis. 54, 84-89. doi: 10.1016/j.bcmd.2014.07.015

Ismael, O., Shimada, A., Elmahdi, S., Elshazley, M., Muramatsu, H., Hama, A., et al. (2014). RUNX1 mutation associated with clonal evolution in relapsed pediatric acute myeloid leukemia with $\mathrm{t}(16 ; 21)(\mathrm{p} 11 ; \mathrm{q} 22)$. Int. J. Hematol. 99, 169-174. doi: 10.1007/s12185-013-1495-5

Jain, N., Curran, E., Iyengar, N. M., Diaz-flores, E., Kunnavakkam, R., Popplewell, L., et al. (2014). Phase II study of the oral MEK inhibitor selumetinib in advanced acute myelogenous leukemia : a university of chicago phase II consortium trial. Clin. Cancer Res. 20, 490-498. doi: 10.1158/1078-0432.CCR-13-1311

Jay, Y., and Schiffer, C. A. (2012). Genetic biomarkers in acute myeloid leukemia: will the promise of improving treatment outcomes be realized? Expert Rev. Hematol. 5, 395-407. doi: 10.1586/ehm.12.32

Jones, D., Yao, H., Romans, A., Dando, C., Pierce, S., Borthakur, G., et al. (2010). Modeling interactions between leukemia-specific chromosomal changes, somatic mutations, and gene expression patterns during progression of core-binding factor leukemias. Genes Chromosomes Cancer 49, 182-191. doi: 10.1097/OPX.0b013e3182540562

Kanehisa, M., Sato, Y., Kawashima, M., Furumichi, M., and Tanabe, M. (2016). KEGG as a reference resource for gene and protein annotation. Nucleic Acids Res. 44, D457-D462. doi: 10.1093/nar/gkv1070

Kao, H. W., Liang, D. C., Wu, J. H., Kuo, M. C., Wang, P. N., Yang, C. P., et al. (2014). Gene mutation patterns in patients with minimally differentiated acute myeloid leukemia. Neoplasia 16, 481-488. doi: 10.1016/j.neo.2014.06.002

Kao, H., Liang, D., Kuo, M., Wu, J., Dunn, P., Wang, P., et al. (2015). High frequency of additional gene mutations in acute myeloid leukemia with MLL partial tandem duplication : DNMT3A mutation is associated with poor prognosis. Oncotarget 6, 33217-33225. doi: 10.18632/oncotarget.5202

Kaspers, G. J., Zimmermann, M., Reinhardt, D., Gibson, B. E., Tamminga, R. Y., Aleinikova, O., et al. (2013). Improved outcome in pediatric relapsed acute myeloid leukemia: results of a randomized trial on liposomal daunorubicin by the international BFM study group. J. Clin. Oncol. 31, 599-607. doi: 10.1200/JCO.2012.43.7384

Katoh, M., and Katoh, M. (2003). Identification and characterization of ASXL2 gene in silico. Int. J. Oncol. 23, 845-850. doi: 10.3892/ijo.26.2.551

Kawahara, M. P., Bartholdy, A., Barreyro, B., Will, L., Roth, B., OkoyeOkafor, M., et al. (2012). H2.0-like homeobox (HLX) regulates early hematopoiesis and promotes acute myeloid leukemia. Cancer Cell 22, 194-208. doi: 10.1016/j.immuni.2010.12.017

Khan, S. N., Jankowska, A. M., Mahfouz, R., Dunbar, A. J., Sugimoto, Y., Hosono, N., et al. (2013). Multiple mechanisms deregulate EZH2 and histone H3 lysine 27 epigenetic changes in myeloid malignancies. Leukemia 27, 1301-1309. doi: $10.1038 /$ leu.2013.80 
Kim, J., He, X., Orr, B., Wutz, G., Hill, V., Peters, M., et al. (2016). Intact cohesion, anaphase, and chromosome segregation in human cells harboring tumor-derived mutations in STAG2. PLoS Genet.12:e1005865. doi: 10.1371/journal.pgen.1005865

Knapper, S., Russell, N., Gilkes, A., Hills, R. K., Gale, R. E., Cavenagh, J. D., et al. (2017). A randomized assessment of adding the kinase inhibitor lestaurtinib to fi rst-line chemotherapy for FLT3-mutated AML. Blood 129, 1143-1154. doi: 10.1182/blood-2016-07-730648

Kottaridis, P. D., Gale, R. E., Langabeer, S. E., Frew, M. E., Bowen, D. T., and Linch, D. C. (2002). Studies of FLT3 mutations in paired presentation and relapse samples from patients with acute myeloid leukemia: implications for the role of FLT3 mutations in leukemogenesis, minimal residual disease detection, and possible therapy with FLT3 inhibitors. Blood 100, 2393-2398. doi: 10.1182/blood-2002-02-0420

Kutny, M. A., Alonzo, T. A., Gamazon, E. R., Gerbing, R. B., Geraghty, D., Lange, B., et al. (2015). Ethnic variation of TET2 SNP rs2454206 and association with clinical outcome in childhood AML: a report from the Children's Oncology Group. Leukemia 29, 2424242-2424246. doi: 10.1038/leu.2015.171

Langemeijer, S. M., Jansen, J. H., Hooijer, J., van Hoogen, P., Stevens-Linders, E., Massop, M., et al. (2011). TET2 mutations in childhood leukemia. Leukemia 25, 189-192. doi: 10.1038/leu.2010.243

Larsson, C. A., Cote, G., and Quintás-Cardama, A. (2014). The changing mutational landscape of acute myeloid leukemia and myelodysplastic syndrome. Mol. Cancer Res. 11, 815-827. doi: 10.1158/1541-7786.MCR-12-0695

Lee, L. Y., Hernandez, D., Rajkhowa, T., Smith, S. C., Raman, J. R., and Nguyen, B. (2017). Preclinical studies of gilteritinib, a next-generation FLT3 inhibitor. Blood 129, 257-260. doi: 10.1182/blood-2016-10-745133

Levis, M. (2017). Midostaurin approved for FLT3-mutated AML. Blood 129, 3403-3407. doi: 10.1182/blood-2017-05-782292

Ley, T. J., Ding, L., Walter, M. J., McLellan, M. D., Lamprecht, T., Larson, D. E., et al. (2010). DNMT3A mutations in acute myeloid leukemia. N. Engl. J. Med. 363, 2424-2433. doi: 10.1056/NEJMoa1005143

Li, H. Y., Deng, D. H., Huang, Y., Ye, F. H., Huang, L. L., Xiao, Q., et al. (2015). Favorable prognosis of biallelic CEBPA gene mutations in acute myeloid leukemia patients: a meta-analysis. Eur. J. Haematol. 94, 439-448. doi: 10.1111/ejh.12450

Liang, D. C., Liu, H. C., Yang, C. P., Jaing, T. H., Hung, I. J., Yeh, T. C., et al. (2013). Cooperating gene mutations in childhood acute myeloid leukemia with special reference on mutations of ASXL1, TET2, IDH1, IDH2, and DNMT3A. Blood 121, 2988-2995. doi: 10.1182/blood-2012-06-436782

Lu, C., Ward, P., Kapoor, G., and Rohle, D. (2012). IDH mutation impairs histone demethylation and results in a block to cell differentiation. Nature 483, 474-478. doi: 10.1038/nature10860

Lund, K., Adams, P. D., and Copland, M. (2014). EZH2 in normal and malignant hematopoiesis. Leukemia 28, 44-49. doi: 10.1038/leu.2013.288

Mardis, E. R., Ding, L., Dooling, D. J., Larson, D. E., McLellan, M. D., Chen, K., et al. (2009). Recurring mutations found by sequencing an acute myeloid leukemia genome. N. Engl. J. Med. 361, 1058-1066. doi: 10.1056/NEJMoa0903840

Marková, J., Michková, P., Burčková, K., Brezinová, J., Michalová, K., Dohnalová, A., et al. (2012). Prognostic impact of DNMT3A mutations in patients with intermediate cytogenetic risk profile acute myeloid leukemia. Eur. J. Haematol. 88, 128-135. doi: 10.1111/j.1600-0609.2011.01716.x

Martelli, M. P., Sportoletti, P., Tiacci, E., Martelli, M. F., and Falini, B. (2013). Mutational landscape of AML with normal cytogenetics: biological and clinical implications. Blood Rev. 27, 13-22. doi: 10.1016/j.blre.2012.11.001

Meshinchi, S., and Arceci, R. J. (2007). Prognostic factors and risk-based therapy in pediatric acute myeloid leukemia. Oncologist 12, 341-355. doi: 10.1634/theoncologist.12-3-341

Micol, J. B., Duployez, N., Boissel, N., Petit, A., Geffroy, S., Nibourel, O., et al. (2014). Frequent ASXL2 mutations in acute myeloid leukemia patients with $\mathrm{t}(8 ; 21) /$ RUNX1-RUNX1T1 chromosomal translocations. Blood 124, 1445-1449. doi: 10.1182/blood-2014-04-571018

Miranda, T. B., Cortez, C. C., Yoo, C. B., Liang, G., Abe, M., Kelly, T. K., et al. (2009). DZNep is a global histone methylation inhibitor that reactivates developmental genes not silenced by DNA methylation. Mol. Cancer Ther. 8, 1579-1588. doi: 10.1158/1535-7163.MCT-09-0013
Moore, A. S., Faisal, A., deCastro, D. G., Bavetsias, V., Sun, C., Atrash, B., et al. (2012). Selective FLT3 inhibition of FLT3-ITD+ acute myeloid leukaemia resulting in secondary D835Y mutation: a model for emerging clinical resistance patterns. Leukemia 26, 1462-1470. doi: 10.1038/leu.2012.52

Moore, A. S., Kearns, P. R., Knapper, S., Pearson, A. D., and Zwaan, C. M. (2013). Novel therapies for children with acute myeloid leukaemia. Leukemia 27, 1451-1460. doi: 10.1038/leu.2013.106

Nakao, M., Yokota, S., Iwai, T., Kaneko, H., Horiike, S., Kashima, K., et al. (1996). Internal tandem duplication of the flt 3 gene found in acute myeloid leukemia. Leukemia 10, 1911-1918.

Ofran, Y., and Rowe, J. M. (2013). Genetic profiling in acute myeloid leukaemiawhere are we and what is its role in patient management. Br. J. Haematol. 160, 303-320. doi: 10.1111/bjh.12135

Oran, B., Cortes, J., Beitinjaneh, A., Chen, H., deLima, M., Patel, K., et al. (2016). Allogeneic transplantation in first remission improves outcomes irrespective of FLT3-ITD allelic ratio in FLT3-ITD-positive acute myelogenous leukemia. Biol. Blood Marrow Transplant. 22, 1218-1226. doi: 10.1016/j.bbmt.2016.03.027

Papaemmanuil, E., Gerstung, M., Bullinger, L., Gaidzik, V. I., Paschka, P., Roberts, N. D., et al. (2016). Genomic classification and prognosis in acute myeloid leukemia. N. Engl. J. Med. 374, 2209-2221. doi: 10.1056/NEJMoa1516192

Paschka, P., Schlenk, R. F., Gaidzik, V. I., Habdank, M., Krönke, J., Bullinger, L., et al. (2010). IDH1 and IDH2 mutations are frequent genetic alterations in acute myeloid leukemia and confer adverse prognosis in cytogenetically normal acute myeloid leukemia with NPM1 mutation without FLT3 internal tandem duplication. J. Clin. Oncol. 28, 3636-3643. doi: 10.1200/JCO.2010.28.3762

Pastore, F., Kling, D., Hoster, E., Dufour, A., Konstandin, N. P., Schneider, S., et al. (2014). Long-term follow-up of cytogenetically normal CEBPA-mutated AML. J. Hematol. Oncol. 7, 1-8. doi: 10.1186/s13045-014-0055-7

Patel, J. P., Gönen, M., Figueroa, M. E., Fernandez, H., Sun, Z., Racevskis, J., et al. (2012). Prognostic relevance of integrated genetic profiling in acute myeloid leukemia. N. Engl. J. Med. 366, 1079-1089. doi: 10.1056/NEJMoa1112304

Perl, A. E., Altman, J. K., Cortes, J., Smith, C., Litzow, M., Baer, M. R., et al. (2017). Selective inhibition of FLT3 by gilteritinib in relapsed or refractory acute myeloid leukaemia: a multicentre, first-in-human, open-label, phase 1-2 study. Lancet Oncol. 18, 1061-1075. doi: 10.1016/S1470-2045(17)30416-3

Pollard, J. A., Alonzo, T. A., Gerbing, R. B., Ho, P. A., Zeng, R., Ravindranath, Y., et al. (2010). Prevalence and prognostic significance of KIT mutations in pediatric patients with core binding factor AML enrolled on serial pediatric cooperative trials for de novo AML. Blood 115, 2372-2379. doi: 10.1182/blood-2009-09-241075

Pui, C. H., Carroll, W. L., Meshinchi, S., and Arceci, R. J. (2011). Biology, risk stratification, and therapy of pediatric acute leukemias: an update. J. Clin. Oncol. 29, 551-565. doi: 10.1200/JCO.2010.30.7405

Puumala, S. E., Ross, J. A., Aplenc, R., and Spector, L. G. (2013). Epidemiology of childhood acute myeloid leukemia. Pediatr. Blood Cancer. 60, 728-733. doi: $10.1002 / p b c .24464$

Radhi, M., Meshinchi, S., and Gamis, A. (2010). Prognostic factors in pediatric acute myeloid leukemia. Curr. Hematol. Malig. Rep. 5, 200-206. doi: 10.1007/s11899-010-0060-z

Rakheja, D., Konoplev, S., Jeffrey Medeiros, L., and Chen, W. (2012). IDH mutations in acute myeloid leukemia. Hum. Pathol. 43, 1541-1551. doi: 10.1016/j.humpath.2012.05.003

Rampal, R., and Figueroa, M. E. (2016). Wilms tumor 1 mutations in the pathogenesis of acute myeloid leukemia. Haematologica 101, 672-679. doi: 10.3324/haematol.2015.141796

Renneville, A., Boissel, N., Gachard, N., Naguib, D., Bastard, C., de Botton, S. et al. (2009a). The favorable impact of CEBPA mutations in patients with acute myeloid leukemia is only observed in the absence of associated cytogenetic abnormalities and FLT3 internal duplication. Blood 113, 5090-5093. doi: 10.1182/blood-2008-12-194704

Renneville, A., Boissel, N., Zurawski, V., Llopis, L., Biggio, V., Nibourel, O., et al. (2009b). Wilms tumor 1 gene mutations are associated with a higher risk of recurrence in young adults with acute myeloid leukemia: a study from the acute leukemia french association. Cancer 115, 3719-3727. doi: 10.1002/cncr.24442

Rowe, J. M., Li, X., Cassileth, P. A., Appelbaum, F. R., Schiffer, C. A., Wiernik, P. H., et al. (2005). Very poor survival of patients with AML who relapse after achieving a first complete remission: the eastern cooperative oncology group experience. Blood 106:546. 
Rubio, P., Campos, B., Digiorge, J. A., Gallego, M. S., Medina, A., Rossi, J. G., et al. (2016). NPM1, FLT3 and CEBPA mutations in pediatric patients with AML from Argentina: incidence and prognostic value. Int. J. Hematol. 104, 582-590. doi: 10.1007/s12185-016-2064-5

Rubnitz, J. E., Inaba, H., Leung, W. H., Pounds, S., Cao, X., Campana, D., et al. (2014). Definition of cure in childhood acute myeloid leukemia. Cancer 120, 2490-2496. doi: 10.1002/cncr.28742

Saygin, C., and Carraway, H. E. (2017). Emerging therapies for acute myeloid leukemia. J. Hematol. Oncol. 10, 1-14. doi: 10.1186/s13045-017-0463-6

Schnittger, S., Eder, C., Jeromin, S., Alpermann, T., Fasan, A., Grossmann, V., et al. (2012). ASXL1 exon 12 mutations are frequent in AML with intermediate risk karyotype and are independently associated with an adverse outcome. Leukemia 27, 82-91. doi: 10.1038/leu.2012.262

Schuback, H. L., Arceci, R. J., and Meshinchi, S. (2013). Somatic characterization of pediatric acute myeloid leukemia using next-generation sequencing. Semin. Hematol. 50, 325-332. doi: 10.1053/j.seminhematol.2013.09.003

Shah, M. Y., and Licht, J. D. (2011). DNMT3A mutations in acute myeloid leukemia. Nat. Genet. 43, 289-290. doi: 10.1038/ng0411-289

Shiba, N., Yoshida, K., Shiraishi, Y., Okuno, Y., Yamato, G., Hara, Y., et al. (2016). Whole-exome sequencing reveals the spectrum of gene mutations and the clonal evolution patterns in paediatric acute myeloid leukaemia. $\mathrm{Br}$. J. Haematol. 175, 476-489. doi: 10.1111/bjh.14247

Shih, A. H., Abdel-Wahab, O., Patel, J. P., and Levine, R. L. (2012). The role of mutations in epigenetic regulators in myeloid malignancies. Nat. Rev. Cancer 12, 599-612. doi: 10.1038/nrc3343

Shih, L., Huang, C., Wu, J., Lin, T., Dunn, P., Wang, P., et al. (2002). Internal tandem duplication of FLT3 in relapsed acute myeloid leukemia : a comparative analysis of bone marrow samples from 108 adult patients at diagnosis and relapse. Blood 100, 2387-2392. doi: 10.1182/blood-200201-0195

Shivarov, V., Gueorguieva, R., Stoimenov, A., and Tiu, R. (2013). DNMT3A mutation is a poor prognosis biomarker in AML: results of a meta-analysis of 4500 AML patients. Leuk. Res. 37, 1445-1450. doi: 10.1016/j.leukres.2013.07.032

Shlush, L. I., Zandi, S., Mitchell, A., Chen, W. C., Brandwein, J. M., Gupta, V., et al. (2014). Identification of pre-leukaemic haematopoietic stem cells in acute leukaemia. Nature 506, 328-333. doi: 10.1038/nature13038

Smith, C. C., Wang, Q., Chin, C., Salerno, S., Damon, L. E., Levis, M. J., et al. (2012). Validation of ITD mutations in FLT3 as a therapeutic target in human acute myeloid leukaemia. Nature 485, 260-263. doi: 10.1038/nature 11016

Stein, E. M., and Tallman, M. S. (2016). Emerging therapeutic drugs for AML. Blood 127, 71-78. doi: 10.1182/blood-2015-07-604538

Stein, E. M., Dinardo, C. D., Pollyea, D. A., Fathi, A. T., Roboz, G. J., Altman, J. K., et al. (2017). Enasidenib in mutant IDH2 relapsed or refractory acute myeloid leukemia. Blood 130, 722-731. doi: 10.1182/blood-2017-04-779405

Stone, R. M., Deangelo, D. J., Klimek, V., Galinsky, I., Estey, E., Nimer, S. D., et al. (2005). Patients with acute myeloid leukemia and an activating mutation in FLT3 respond to a small-molecule FLT3 tyrosine kinase inhibitor, PKC412. Blood 105, 54-60. doi: 10.1182/blood-2004-03-0891

Tamaoki, T., Nomoto, H., Takahashi, I., Kato, Y., Morimoto, M., and Tomita, F. (1986). Staurosporine, a potent inhibitor of phospholipid/Ca ${ }^{++}$ dependent protein kinase. Biochem Biophys Res. Commun. 135, 397-402. doi: 10.1016/0006-291X(86)90008-2

Tarlock, K., and Meshinchi, S. (2015). Pediatric acute myeloid leukemia: biology and therapeutic implications of genomic variants. Pediatr. Clin. North Am. 62, 75-93. doi: 10.1016/j.pcl.2014.09.007
Tasian, S. K., Pollard, J. A., and Aplenc, R. (2014). Molecular therapeutic approaches for pediatric acute myeloid leukemia. Front. Oncol. 4:55. doi: 10.3389/fonc.2014.00055

Tawana, K., Wang, J., Renneville, A., Bödör, C., Hills, R., Loveday, C., et al. (2015). Disease evolution and outcomes in familial AML with germline CEBPA mutations. Blood 126, 1214-1223. doi: 10.1182/blood-2015-05-647172

Thol, F., Heuser, M., Damm, F., Klusmann, J. H., Reinhardt, K., and Reinhardt, D. (2011). DNMT3A mutations are rare in childhood acute myeloid leukemia. Haematologica 96, 1238-1240. doi: 10.3324/haematol.2011.046839

Thol, F., Schlenk, R. F., Heuser, M., and Ganser, A. (2015). How I treat refractory and early relapsed acute myeloid leukemia. Blood 126, 319-327 doi: 10.1182/ blood-2014-10-551911

Tie, R., Zhang, T., Fu, H., Wang, L., Wang, Y., He, Y., et al. (2014). Association between DNMT3A mutations and prognosis of adults with de novo acute myeloid leukemia : a systematic review and meta-analysis. PLoS ONE 9:e93353 doi: 10.1371/journal.pone.0093353

Van Vlierberghe, P., Palomero, T., Khiabanian, H., Van der Meulen, J., Castillo, M., Van Roy, N., et al. (2010). PHF6 mutations in T-cell acute lymphoblastic leukemia. Nat. Genet. 42, 338-342. doi: 10.1038/ng.542

Van Vlierberghe, P., Patel, J., Abdel-Wahab, O., Lobry, C., Hedvat, C. V., Balbin, M., et al. (2011). PHF6 mutations in adult acute myeloid leukemia. Leukemia 25, 130-134. doi: 10.1038/leu.2010.247

Weissmann, S., Alpermann, T., Grossmann, V., Kowarsch, a, Nadarajah, N., Eder, C., et al. (2012). Landscape of TET2 mutations in acute myeloid leukemia. Leukemia 26, 934-942. doi: 10.1038/leu.2011.326

Welch, J. S., Ley, T. J., Link, D. C., Miller, C. A., Larson, D. E., Koboldt, D. C., et al. (2012). The origin and evolution of mutations in acute myeloid leukemia. Cell 150, 264-278. doi: 10.1016/j.cell.2012.06.023

Yap, D. B., Chu, J., Berg, T., Schapira, M., Cheng, S. W., Moradian, A., et al. (2011). Somatic mutations at EZH2 Y641 act dominantly through a mechanism of selectively altered PRC2 catalytic activity, to increase H3K27 trimethylation. Blood 117, 2451-2459. doi: 10.1182/blood-2010-11-321208

Yeh, T. C., Marsh, V., Bernat, B. A., Ballard, J., Colwell, H., Evans, R. J., et al. (2007). Biological characterization of ARRY-142886 (AZD6244), a potent, highly selective mitogen-activated protein kinase kinase $1 / 2$ inhibitor. Clin. Cancer Res. 13, 1576-1583. doi: 10.1158/1078-0432.CCR-06-1150

Yoshida, K., Toki, T., Okuno, Y., Kanezaki, R., Shiraishi, Y., Sato-Otsubo, A., et al. (2013). The landscape of somatic mutations in Down syndrome-related myeloid disorders. Nat. Genet. 45, 1293-1299. doi: 10.1038/ng.2759

Zarrinkar, P. P., Gunawardane, R. N., Cramer, M. D., Gardner, M. F., Brigham, D., Belli, B., et al. (2009). AC220 is a uniquely potent and selective inhibitor of FLT3 for the treatment of acute myeloid leukemia (AML). Blood 114, 2984-2992. doi: 10.1182/blood-2009-05-222034

Zhang, H., Mi, J. Q., Fang, H., Wang, Z., Wang, C., Wu, L., et al. (2013). Preferential eradication of acute myelogenous leukemia stem cells by fenretinide. Proc. Natl. Acad. Sci. U.S.A. 110, 5606-5611. doi: 10.1073/pnas.1302352110

Conflict of Interest Statement: The authors declare that the research was conducted in the absence of any commercial or financial relationships that could be construed as a potential conflict of interest.

Copyright (c) 2017 Aziz, Ping, Alias, Ab Mutalib and Jamal. This is an open-access article distributed under the terms of the Creative Commons Attribution License (CC $B Y)$. The use, distribution or reproduction in other forums is permitted, provided the original author(s) or licensor are credited and that the original publication in this journal is cited, in accordance with accepted academic practice. No use, distribution or reproduction is permitted which does not comply with these terms. 